\title{
Cardioprotective effect of aminoguanidine in combination with steroid therapy after blunt chest trauma
}

\author{
Duran L 1 , Guzel A ${ }^{2}$, Akdemir HU ${ }^{1}$, Demir F ${ }^{3}$, Karadeniz $\mathrm{C}^{4}$, Alacam $\mathrm{H}^{5}$, Gacar $\mathrm{A}^{6}$, Murat $\mathrm{N}^{7}$, \\ Ozdemir $\mathrm{S}^{2}$, Guvenc $\mathrm{T}^{6}$
}

Ondokuz Mayis University, Faculty of Medicine, Department of Emergency Medicine, Samsun, Turkey. lduran@omu.edu.tr

\begin{abstract}
Background: Cardiac contusion is an important cause of mortality after blunt chest trauma (BCT). The aim of this study was to investigate the therapeutic efficacy of the usage of aminoguanidine (AG), in myocardial damage occurring after BCT, alone and in combination with methylprednisolone (MP).

Methods: Thirty-five female Wistar albino rats were randomly assigned to five groups $(n=7)$ including: sham controls (S); only cardiac contusion (CONT); cardiac contusion treated with methylprednisolone (CONT+MP); cardiac contusion treated with aminoguanidine (CONT+AG); and cardiac contusion treated with methylprednisolone and aminoguanidine (CONT+MP+AG). Seven days following the treatments, heart and serum specimens were evaluated histopathologically, immunohistochemically, and biochemically in all groups.

Results: Serum AOPP and Tn-I levels increased significantly after cardiac contusions. Haemorrhage, tissue degeneration, and necrosis development was evident following contusions. Increased iNOS expression in myocardial tissue was significantly decreased in the CONT+AG+MP group compared to CONT+AG and CONT+MP groups ( $p=0.001$ and $p=0.011$, respectively). The combined treatment of AG and MP increased Bcl-2 expression significantly after contusions compared to the other treatment groups.

Conclusions: Combined usage of AG, a selective iNOS inhibitor, with MP, in cardiac contusions, showed a more powerful cardioprotective effect by increasing Bcl-2 expression and reducing iNOS expression (Tab. 3, Fig. 4, Ref. 33). Text in PDF www.elis.sk.

Key words: cardiac contusion, blunt chest trauma, iNOS, Bcl-2, methylprednisolone, aminoguanidine.
\end{abstract}

Mortality rates in blunt chest trauma (BCT) patients, which make up $10 \%$ of emergency room trauma patients worldwide, range from $4 \%$ to $20 \%(1,2)$. Risk factors effecting the mortality and morbidity in these patients include advanced age ( $\geq 65$ years), three or more concomitant rib fractures, cardiopulmonary disease, coexistence of other systemic injuries, post-traumatic pneumonia, and cardiac injury occurring after trauma (1-3).

Cardiac injury occurring in BCT is one cause of mortality in the early periods in these patients (2). However, there is a little clarity on its frequency in blunt chest trauma. Nevertheless, studies reported that cardiac injury occured at rates of $0 \%$ to $76 \%$ after BCT (3). In determining the severity of cardiac damage in blunt chest trauma, measurements of cardiac enzymes, such as CK-MB, cTn-I, and cTn-T are analyzed. Additionally, electrocardiography,

${ }^{1}$ Ondokuz Mayis University, Faculty of Medicine, Department of Emergency Medicine, Samsun, Turkey, ${ }^{2}$ Ondokuz Mayis University, Faculty of Medicine, Department of Pediatrics, Samsun, Turkey, ${ }^{3}$ Behçet Uz Children's Hospital, Pediatric Cardiology Services, Izmir, Turkey, ${ }^{4}$ Diyarbakir Training and Research Hospital, Pediatric Cardiology Services, Diyarbakir, Turkey, ${ }^{5}$ Ondokuz Mayis University, Faculty of Medicine, Department of Medical Biochemistry, Samsun, Turkey, ${ }^{6}$ Ondokuz Mayis University, Faculty of Veterinary Medicine, Department of Pathology, Samsun, Turkey, and ${ }^{7}$ Ondokuz Mayis University, Department of Industrial Engineering, Samsun, Turkey

Address for correspondence: L. Duran, MD, Ondokuz Mayis University, Faculty of Medicine, Department of Emergency Medicine, Kurupelit, 55139, Samsun, Turkey.

Phone: +90.362.3121919-3111, Fax: +90.362.4576041 echocardiography, angiography, and CT imaging methods are frequently used (2-4). However, these diagnostic methods alone are not effective in determining the severity of cardiac damage.

Cellular and molecular mechanisms of cardiac damage occurring after a contusion have not been clearly elucidated. After a cardiac contusion, in addition to microscopic changes such as ruptures in cardiac membranes, haemorrhage, hematomas, and blood clots in small venous structures may occur. Additionally, macroscopic changes such as diapedesis erythrocyte, neutrophiles and macrophage migration, interstitial edema, myocardial muscle fibres dissociation and relaxation, and segmental contracture may occur as an inflammatory response (5). There is no specific treatment regimen for cardiac contusions since cellular and molecular pathogenesis, which play a role in myocardial injury-induced changes, are not entirely known. However, anti-inflammatory steroids are effective in experimental studies by preventing apoptosis due to myocardial injury and suppressing the anti-inflammatory process $(6,7)$.

Nitric oxide (NO) has protective effects on the cardiovascular system. However, the negative impact of excessive increased amounts of NO on the circulatory system after myocardial damage has been shown in animal studies (8-11). NO is produced by three nitric oxide synthase (NOS) isoforms, endothelial NOS (eNOS), neuronal NOS (nNOS), and inducible NOS (iNOS) (12). iNOS is released by endothelium, epithelium, and inflammatory cells. The excessive release of NO produced by iNOS that have 
associated it with oxidative injury. Specifically, aminoguanidine, a selective iNOS inhibitor, has cardioprotective effects following an ischemic injury (9-11).

In this study, the effect of the combined usage of MP with aminoguanidine, a selective iNOS inhibitor, on cardiac recovery in the treatment of cardiac contusions occurring after blunt chest trauma, was investigated.

\section{Materials and methods}

Thirty-five female Wistar albino rats (250-300 g) were used for this study. All rats were maintained under standard experimental laboratory conditions (temperature: $24{ }^{\circ} \mathrm{C}$; dark/light cycle: 12/12 h; free access to food and water; relative humidity: $60 \%$ ). All animal procedures were approved by the Experimental Animal Studies Ethics Committee of Ondokuz Mayis University.

All experimental rats were randomly assigned to 5 groups $(n=7$ per group). The groups included: sham controls (S), cardiac contusion only (CONT), cardiac contusion treated only with methylprednisolone (CONT+MP; Prednol-L 20 mg, Mustafa Nevzat, Turkey); cardiac contusion treated only with aminoguanidine $(\mathrm{CONT}+\mathrm{AG}$; Sigma Chemical Co., St. Louis, Mo, U.S.A); and cardiac contusion treated with the same dose of methylprednisolone and aminoguanidine $(\mathrm{CONT}+\mathrm{MP}+\mathrm{AG}) . \mathrm{AG}$ and $\mathrm{MP}$ were dissolved in saline $(0.9 \% \mathrm{NaCl} w / \mathrm{v})$. Treatment procedures and drug dosages applied to all experimental groups are shown in the Table $1(13,14)$.

All rats were anesthetized with an intraperitoneal (ip) injection of ketamine hydrochloride $(100 \mathrm{mg} / \mathrm{kg})$ and xylazine $(10 \mathrm{mg} / \mathrm{kg})$. The sedated rats were placed in the supine position on Plexiglas boards. A blunt chest trauma model described by Raghavendran et al (15) was used. The impact energy of $1.96 \mathrm{~J}$ was applied to the chest wall. The impact energy (E; in Joules, J) of the falling weight was calculated from the equation: $\mathrm{E}=\mathrm{mgh}(16)$, where $\mathrm{m}$ is the mass of the falling aluminum weight $(0.4 \mathrm{~kg}), \mathrm{g}$ is gravitational acceleration $\left(9.8 \mathrm{~m} / \mathrm{s}^{2}\right)$, and $\mathrm{h}$ is the height of the weight $(50 \mathrm{~cm})$ above the Lexon platform. All experimental rats were observed until they recovered from the procedure.

At the end of the seventh day, all rats were administered an ip injection of ketamine hydrochloride and sacrificed. After the rats were sacrificed, the hearts were removed promptly for histopathological evaluations.

Tab. 1. Treatment regimes in all study groups.

\begin{tabular}{|c|c|c|}
\hline Study groups & $\begin{array}{c}\text { First day } \\
\text { (single dose (ip), } \\
5 \text { min after contusion) }\end{array}$ & $\begin{array}{c}2 .-7 . \text { day } \\
\text { (ip, once a day) }\end{array}$ \\
\hline $\bar{S}$ & NT & NT \\
\hline CONT & NT & NT \\
\hline $\mathrm{CONT}+\mathrm{AG}$ & $\mathrm{AG}(200 \mathrm{mg} / \mathrm{kg}) 15$ & $\mathrm{AG}(200 \mathrm{mg} / \mathrm{kg})$ \\
\hline $\mathrm{CONT}+\mathrm{MP}$ & MP (30 mg/kg bolus) 14 & $\mathrm{MP}(3 \mathrm{mg} / \mathrm{kg})$ \\
\hline$\overline{\mathrm{CONT}}+\mathrm{MP}+\mathrm{AG}$ & $\begin{array}{l}\text { MP (30 mg/kg bolus) } \\
+ \text { AG }(200 \mathrm{mg} / \mathrm{kg})\end{array}$ & $\begin{aligned} & \mathrm{MP}(3 \mathrm{mg} / \mathrm{kg}) \\
+ & \mathrm{AG}(200 \mathrm{mg} / \mathrm{kg})\end{aligned}$ \\
\hline \multicolumn{3}{|c|}{$\begin{array}{l}\mathrm{S}=\text { Sham, } \mathrm{CONT}=\text { Cardiac contusion, } \mathrm{CONT}+\mathrm{MP}=\mathrm{CONT} \text { group treated with } \\
\text { Methylprednisolone, } \mathrm{CONT}+\mathrm{AG}=\mathrm{CONT} \text { group treated with Aminoguanidine, } \\
\mathrm{CONT}+\mathrm{MP}+\mathrm{AG}=\mathrm{CONT} \text { group treated with Methylprednisolone and Aminogua- } \\
\text { nidine, } \mathrm{MP}=\text { Methylprednisolone, } \mathrm{AG}=\text { Aminoguanidine, ip = intraperitoneal, } \\
\mathrm{NT}=\text { No treatment. }\end{array}$} \\
\hline
\end{tabular}

\section{Biochemical procedure}

Preparation of the samples

After sacrifice, bloods samples were collected into test tubes. The whole blood samples were allowed to clot at room temperature for 30 minutes. These samples were then centrifuged at 3000 $\mathrm{x} g$ for 10 minutes at $4{ }^{\circ} \mathrm{C}$. Following centrifugation, the serum was removed and transferred into a clean tube. All samples were stored at $-80^{\circ} \mathrm{C}$ until analysis. A day before the study, all samples were dissolved at $2-8^{\circ} \mathrm{C}$.

Measurement of serum advanced oxidation protein products (AOPP) levels

AOPP was studied in line with the directions of the manufacturer (Immundiagnostik AG, Stubenwald-Allee 8a, D 64625 Bensheim, Germany). The principle of the test is based on a spectroscopic analysis of modified proteins at $340 \mathrm{~nm}$. The results are presented in $\mu \mathrm{mol} / 1$.

Measurement of serum troponin I (TN-I) levels

Tn-I levels were studied in line with the directions of the manufacturer (Hangzhou Eastbiopharm Co. Ltd., Hangzhou, China). The test is based on a sandwich enzyme immunoassay. The plate was pre-coated with an antibody specific to Tn-I. Samples were added to the wells with a biotin-conjugated antibody specific to Tn-I. Next, avidin conjugated to horseradish peroxidase was added to the wells and incubated. After chromogen solutions were added, the enzyme-substrate reaction was terminated by the addition of an acid solution and the colour change was measured photometrically at $450 \mathrm{~nm}$. The concentration of Tn-I in the samples was determined by the standard curve. The results are presented in $\mathrm{pg} / \mathrm{ml}$.

\section{Histopathological studies}

Thirty-five rats were used to determine the effects of a contusion on heart tissue by immunohistochemistry and histopathology. The hearts were rapidly excised and were fixed in $10 \%$ buffered formalin for 24-72 hours and embedded in paraffin after routine procedure. Sections of $5 \mu \mathrm{m}$ thickness were prepared from the blocks and stained with hematoxilene-eosin (HE) for routine microscopic examination. Subsequently, pathologists blinded to the control and study groups examined all microscopic slides. Necrosis, degeneration, haemorrhage and calcification in myocardial tissue was scored from 0 to 3 with $0=$ negative, $1=$ weak, $2=$ moderate, and $3=$ severe.

\section{Immunohistochemistry procedure}

Heart tissue samples were trimmed and fixed in $10 \%$ neutral buffered formalin and embedded in paraffin. All samples were sectioned at a thickness of $5 \mu \mathrm{m}$ and were deparaffinized and rehydrated. The streptavidin-biotin-peroxidase complex (SBPC) technique (Histostain Plus Kit; Zymed, cat no: 85-8943, California, USA) was used for the immunohistochemical study. Endogenous peroxidase activity was removed by incubation with $2 \%$ hydrogen peroxidase in methanol for $30 \mathrm{~min}$ at room temperature. Antigen retrieval was performed by microwave treatment for $15 \mathrm{~min}$ in a citrate buffer ( $\mathrm{pH}$ 6.0). Rabbit polyclonal anti-inducible nitric oxide synthase (iNOS) antibodies (1/250; Abcam, cat no: ab3523, UK) and anti Bcl-2 antibodies (1/250; Abcam, cat no: ab7973, UK) 
were used as primary antibodies. Aminoethylcarbazole was used as the chromogen in $\mathrm{H}_{2} \mathrm{O}_{2}$ for 10 minutes, which was controlled by visual observation with a microscope. The sections were counter stained with Lillie Mayer's hematoxylin for one minute and rinsed with tap water. Subsequently, the sections were mounted with an aqueous mounting medium. Immunohistochemical anti-iNOS and anti Bcl-2 staining of the heart tissue slides was evaluated semiquantitatively according to the intensity for the differences between each experimental group. Staining intensity of iNOS and Bcl-2 were recorded as faint $(-/+)$, mild $(+)$, moderate $(++)$, and strong $(+++)$. The evaluation of immunostaining was performed in at least eight randomly selected areas per heart section, using two sections from each animal at $400 \times$ magnification. The final score calculated in each category for each individual rat was the mean of the scores from the sections of the hearts examined.

\section{Statistical methods}

All findings were evaluated with the SPSS 21.0 package software. All findings are represented as median (minimum/maximum) or mean \pm standard deviation. All measurements were compared to Mann-Whitney U and independent samples $t$-tests according to the distribution of data. An index of probability of less than 0.05 $(p<0.05)$ was considered significant.

\section{Results}

\section{Tn-I levels}

Serum Tn-I levels were significantly increased in the CONT group compared to the $\mathrm{S}$ group $(\mathrm{p}=0.038)$. MP treatment decreased serum Tn-I levels in the CONT+MP group compared to the CONT group; however, these changes were not statistically significant ( $p$ $=0.259$ ). After AG treatment, Tn-I levels were significantly decreased in the CONT $+\mathrm{AG}$ group compared to the CONT group $(p=0.017)$. Serum Tn-I levels were not significantly decreased in the CONT $+\mathrm{MP}+\mathrm{AG}$ group compared to the CONT group ( $\mathrm{p}$ $=0.128$ ). When treatment groups were compared to each other, serum Tn-I levels were statistically decreased with AG treatment compared to MP treatment and the combined MP+AG treatment $(\mathrm{p}=0.038$ and $\mathrm{p}=0.038$, respectively). A comparison of serum Tn-I levels between all groups with statistically significant differences is represented in the Figure 1.

\section{AOPP levels}

After contusions, AOPP levels were significantly increased in the CONT group compared to the $\mathrm{S}$ group $(\mathrm{p}=0.001)$ (Fig. 2). The decrease in AOPP levels was not statistically significant in the CONT+MP group compared to the CONT group $(p=0.209)$. Serum AOPP levels were significantly decreased in the CONT + AG group compared to the CONT group $(p=0.017)$ (Fig. 2). After the combined $\mathrm{MP}+\mathrm{AG}$ treatment, serum AOPP levels were significantly decreased in the $\mathrm{CONT}+\mathrm{MP}+\mathrm{AG}$ group compared to the CONT group $(p=0.026)$ (Fig. 2). There were no statistically significant changes in AOPP levels in the CONT+AG+MP group compared to the CONT $+\mathrm{MP}$ and CONT $+\mathrm{AG}$ groups $(\mathrm{p}=0.383$ and $\mathrm{p}=0.383$, respectively).

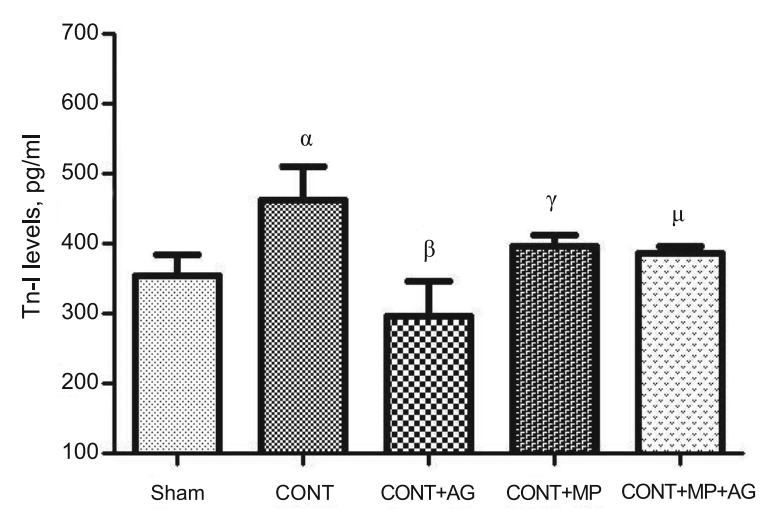

Fig. 1. Comparison of Tn-I levels of all study groups with statistically significances. ${ }^{\alpha} p=0.038$ compared to Sham group, ${ }^{\beta} p=0.026 \mathrm{com}-$ pared to CONT group, ${ }^{\gamma} \mathbf{p}=\mathbf{0 . 0 3 8}$ compared to CONT + AG group, ${ }^{\mu}$ $\mathrm{p}<\mathbf{0 . 0 5}$ compared to $\mathrm{CONT}+\mathrm{AG}$ group.

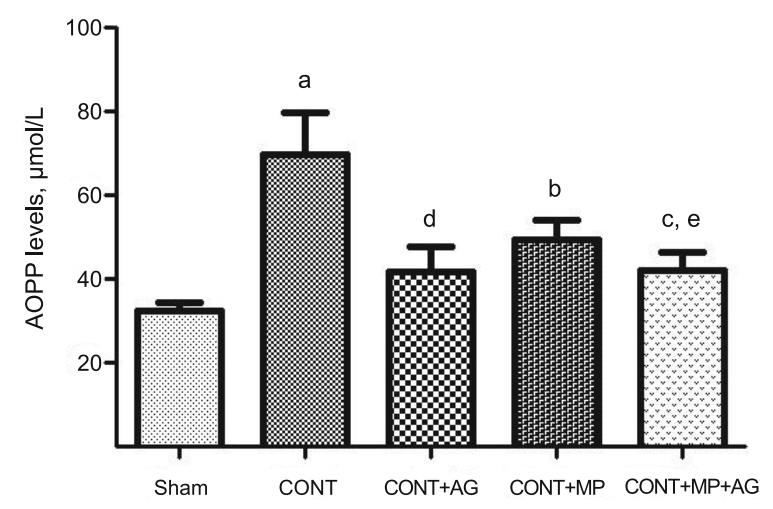

Fig. 2. Comparison of AOPP levels of all study groups with statistically significances. ${ }^{a} p=0.001$ compared to Sham group, ${ }^{b} p=0.001$ compared to Sham group, ${ }^{\mathrm{c}} \mathbf{p}=\mathbf{0 . 0 3 8}$ compared to Sham group, ${ }^{\mathrm{d}} \mathbf{p}=$ 0.017 compared to CONT group, ${ }^{\mathrm{e}} \mathrm{p}=\mathbf{0 . 0 2 6}$ compared to CONT group.

\section{Histopathological results}

The cardiac tissues removed from the CONT group had severe histopathological changes including haemorrhage, degeneration, and necrosis (Fig. 3). In the AG treatment group, haemorrhage and necrosis scores were statistically less than those observed in the CONT group (Tab. 2). However, only degeneration scores in the $\mathrm{CONT}+\mathrm{MP}$ group were statistically less than the CONT group. In the $\mathrm{CONT}+\mathrm{AG}+\mathrm{MP}$ group, all histopathological scores in the cardiac tissue were less than other treatment groups compared to the CONT group (Tab. 2).

\section{Immunohistochemical results}

iNOS findings

In the sham control group, iNOS positive cells were rarely detected (Fig. 4e1, Tab. 3). The iNOS positive cells were strongly determined in the cardiac tissue removed from CONT group (Fig. 4a1, Tab. 3). In the $\mathrm{CONT}+\mathrm{AG}$ and $\mathrm{CONT}+\mathrm{MP}$ groups, $\mathrm{iNOS}$ positive expressions were moderate (Figs $4 \mathrm{~b} 1$ and $4 \mathrm{c} 1$ ). The median number of iNOS positive cell numbers was significantly different between the $\mathrm{CONT}+\mathrm{AG}+\mathrm{MP}$ group and other treatment groups (Tab. 3, Fig. 4d1). 


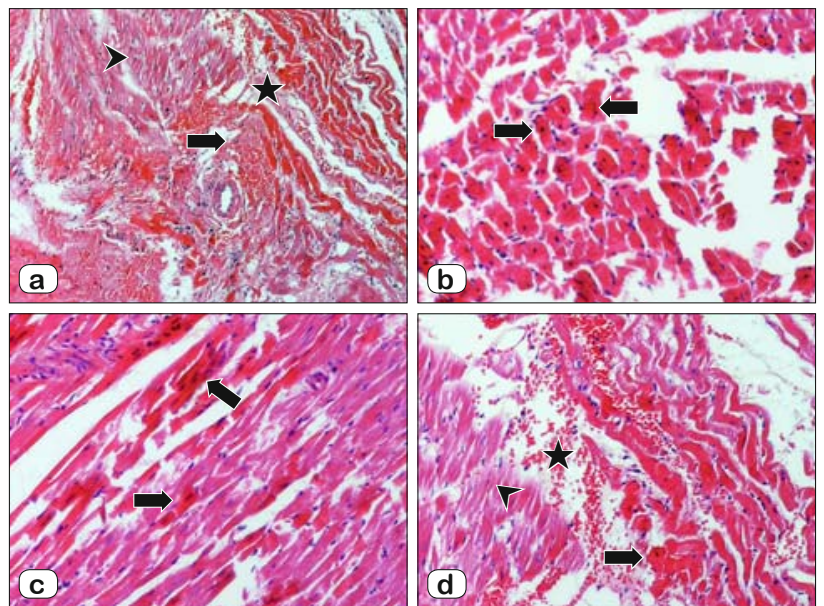

Fig. 3. Histochemical Evaluation. a) There is an excessive haemorrhage between myocardiocytes (five point star), necrotic cardiac cells with picnotic nucleus (arrow) and degeneration of cardiocytes (arrow head) in CONT group, x10. b) severe necrosis and necrotic cells (arrow) in ruptured area of heart in CONT group, $x$ 20. c) longitudinal sections of myocardiocytes and necrotic cells (arrow) in CONT group, $x$ 20. d) the interstitial area is fulfilled with erythrocytes (five point star), necrotic (arrow) and degenerated (arrow head) cardiac cells in CONT group, $\mathbf{x 2 0}$.

\section{Bcl-2 findings}

Bcl-2 positive cells were rarely detected in the CONT group (Fig. 4a2, Tab. 3), but these changes were statistically significant compared to the sham group (Fig. 4e2, Tab. 3). In the CONT+AG and $\mathrm{CONT}+\mathrm{MP}$ groups, the same $\mathrm{Bcl}-2$ positive cell numbers in cardiac tissue were observed (Figs $4 \mathrm{~b} 2$ and 4c2, Tab. 3). However, the Bcl-2 immunopositive cell numbers score was significantly higher in the $\mathrm{CONT}+\mathrm{AG}+\mathrm{MP}$ group (median $3+$ ) than in the treatment groups (median 2+) (Tab. 3, Fig. 4d2).

\section{Discussion}

The aim of this study was to determine histopathological changes occurring in heart tissue after cardiac contusion in the contusion model. Additionally, the goal was to investigate the role of iNOS and Bcl-2, which is thought to play a role in the pathogenesis of cardiac damage. Further aims were to investigate the effect of the combined usage of aminoguanidine, a NOS inhibitor, with anti-inflammatory effective methylprednisolone on cardiac tissue and aid in the development of therapeutic strategies in this issue.

Patients with severe chest trauma constitute one-third of all trauma patients admitted to hospitals and $20 \%$ to $25 \%$ of the deaths occurring in these patients are related to chest trauma (17, 18). The main reason for the majority of these deaths is due to trauma causing a cardiovascular injury. This type of trauma is generally associated with motor vehicle accidents, sports activities (baseball, hockey puck, etc.), and work-related injuries $(19,20)$. Direct precordial impact, crush injury resulting from compression between the sternum and vertebrae, and deceleration or torsion are among the mechanisms causing cardiac damage in this type of fatal blunt chest trauma (20).
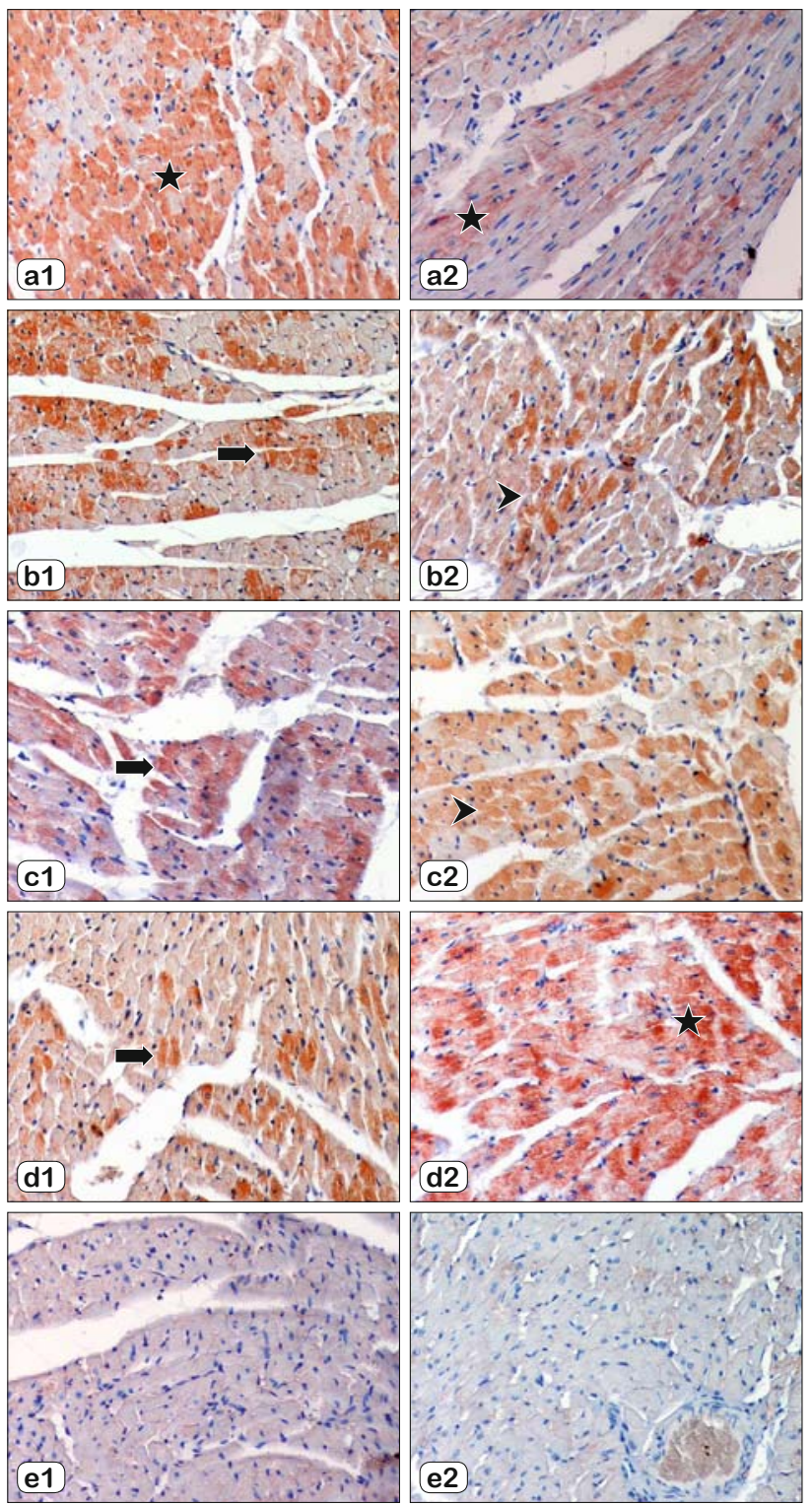

Fig. 4. Immunohistochemical study of cardiac tissues incubated with anti-iNOS and anti-Bcl-2 antibody. a1) Strongly iNOS immunopositive cardiac muscle cells (five point star) in CONT group. b1) Moderate immunopositive reaction of iNOS in heart tissues and the arrow shows the immunopositive cells in CONT + AG group. c1) moderate iNOS immunopositivity (arrow) in CONT+MP group. d1) weakly iNOS immunopositive cardiac muscle cells (arrow) in CONT +AG+MP group. e1) there is no immunopositive reaction in Sham group.

a2) weakly Bcl-2 immunopositive cell reaction (star) in CONT group. b2) moderate Bcl-2 immunopositivity (arrow) in CONT+AG group. c2) Moderate immunopositive reaction of Bcl-2 in heart tissues and the arrow shows the immunopositive cells in CONT $+M P$ group d2) Strongly Bcl-2 immunopositive cardiac muscle cells (five point star) in CONT+AG+MP group. e2) no immunopositive Bcl-2 reaction in Sham group. Immunoperoxidase technique, Lillie Mayer Alum Hematoxylen counterstaining, AEC as a chromogen, $\mathbf{x 2 0}$.

Cardiac contusion scan cause life-threatening disorders including complex cardiac arrhythmias, hypotension, cardiogenic shock, hemopericardium, coronary vessel and valvular injury, 
Tab. 2. Evaluation of HEM, DEG, and NEC scores between in all study groups.

\begin{tabular}{|c|c|c|c|c|c|}
\hline & $\mathrm{S}$ & CONT & $\mathrm{CONT}+\mathrm{AG}$ & $\mathrm{CONT}+\mathrm{MP}$ & $\mathrm{CONT}+\mathrm{MP}+\mathrm{AG}$ \\
\hline HEM & $\begin{array}{c}0+ \\
(0+/ 1+)\end{array}$ & $\begin{array}{c}1+\dagger \\
(0+/ 3+)\end{array}$ & $\begin{array}{c}0+\& \\
(0+/ 1+)\end{array}$ & $\begin{array}{c}0+ \\
(0+/ 2+)\end{array}$ & $\begin{array}{c}0+\alpha \\
(0+/ 1+)\end{array}$ \\
\hline$\overline{\mathrm{DEG}}$ & $\begin{array}{c}0+ \\
(0+/ 1+)\end{array}$ & $\begin{array}{c}3+\dagger \\
(1+/ 3+)\end{array}$ & $\begin{array}{c}1+ \\
(0+/ 3+)\end{array}$ & $\begin{array}{c}1+\& \\
(0+/ 2+)\end{array}$ & $\begin{array}{c}1+\& \\
(0+/ 1+)\end{array}$ \\
\hline$\overline{\mathrm{NEC}}$ & $0+$ & $\begin{array}{c}2+{ }^{\#} \\
(2+/ 3+)\end{array}$ & $\begin{array}{c}1+\& \\
(0+/ 3+)\end{array}$ & $\begin{array}{c}2+ \\
(0+/ 2+)\end{array}$ & $\begin{array}{c}1+\mu \\
(0+/ 1+)\end{array}$ \\
\hline
\end{tabular}

All values were expressed as median (minimum/maximum). $\mathrm{S}=$ Sham, CONT $=$ Cardiac Contusion, $\mathrm{CONT}+\mathrm{AG}=\mathrm{CONT}$ group treated with Aminoguanidin, $\mathrm{CONT}+\mathrm{MP}$ $=\mathrm{CONT}$ group treated with Methylprednisolone, $\mathrm{CONT}+\mathrm{MP}+\mathrm{AG}=\mathrm{CONT}$ group treated with Methylprednisolone and Aminoguanidin. $\mathrm{HEM}=\mathrm{Haemorrhage}, \mathrm{DEG}=$ Degeneration, NEC $=$ Necrosis. ${ }^{\dagger} \mathrm{p}=0.001$ compared to Sham group, ${ }^{\#} \mathrm{p}=0.026$ compared to Sham group, ${ }^{\&} \mathrm{p}=0.026$ compared to CONT group, ${ }^{\alpha} \mathrm{p}=0.001$ compared to CONT group, ${ }^{\mu} \mathrm{p}=0.011$ compared to CONT group.

Tab. 3. Comparison of iNOS and BCL-2 expressions in all study groups.

\begin{tabular}{|c|c|c|c|c|c|}
\hline & $\mathrm{S}$ & CONT & $\mathrm{CONT}+\mathrm{AG}$ & CONT+MP & $\mathrm{CONT}+\mathrm{MP}+\mathrm{AG}$ \\
\hline$\overline{\mathrm{iNOS}}$ & $\begin{array}{c}0+ \\
(0+/ 1+)\end{array}$ & $\begin{array}{c}3+{ }^{*} \\
(2+/ 3+)\end{array}$ & $\begin{array}{c}1+\dagger \\
(0+/ 2+)\end{array}$ & $\begin{array}{c}2+\beta \\
(1+/ 2+)\end{array}$ & $\begin{array}{c}0+\uparrow, \mu, \& \\
(0+/ 1+)\end{array}$ \\
\hline$\overline{\text { BCL-2 }}$ & $\begin{array}{c}0+ \\
(0+/ 1+)\end{array}$ & $\begin{array}{c}1+ \\
(0+/ 2+)\end{array}$ & $\begin{array}{c}2+ \\
(1+/ 2+)\end{array}$ & $\begin{array}{c}2+ \\
(1+/ 3+)\end{array}$ & $\begin{array}{c}3+t, a, \# \\
(2+/ 3+)\end{array}$ \\
\hline
\end{tabular}

All values were expressed as median (minimum/maximum). $\mathrm{S}=$ Sham, $\mathrm{CONT}=$ Cardiac Contusion, $\mathrm{CONT}+\mathrm{AG}=\mathrm{CONT}$ group treated with Aminoguanidin, $\mathrm{CONT}+\mathrm{MP}$ $=\mathrm{CONT}$ group treated with Methylprednisolone, $\mathrm{CONT}+\mathrm{MP}+\mathrm{AG}=\mathrm{CONT}$ group treated with Methylprednisolone and Aminoguanidin. $\mathrm{HEM}=\mathrm{Haemorrhage}, \mathrm{DEG}=$ Degeneration, NEC $=$ Necrosis. ${ }^{~} \mathrm{p}=0.001$ compared to Sham group,${ }^{\dagger} \mathrm{p}=0.001$ compared to CONT group, ${ }^{\beta} \mathrm{p}=0.002$ compared to CONT group, ${ }^{\mu} \mathrm{p}=0.001$ compared to CONT $+\mathrm{MP}$ group, ${ }^{\alpha} \mathrm{p}=0.011$ compared to CONT $+\mathrm{MP}$ group, ${ }^{\&} \mathrm{p}=0.011$ compared to CONT $+\mathrm{AG}$ group, ${ }^{\#} \mathrm{p}=0.004$ compared to $\mathrm{CONT}+\mathrm{AG}$ group.

and cardiac rupture (21-23). However, the microscopic changes at the cellular level causing minor ECG or enzyme abnormalities occur in cardiac contusion after BCT (23). These microscopic changes are necrosis of myocardial muscle fibres, red blood cell and polymorphonuclear leukocyte migration into myocardial tissue, haemorrhage, and edema (19). In our study, haemorrhage in myocardial tissue, degeneration, and necrosis were quite evident following BCT.

Molecular and physiological changes occurring with cardiac contusions have not been clearly elucidated. Therefore, treatment of cardiac contusions include symptomatic approaches such as ensuring the security of airways, intravenous fluid replacement, and treatment of concomitant arrhythmias rather than the treatment of cardiac damage (22-24). Damage occurring at the cellular level due to hypoxia and tissue hypoperfusion after BCT have been reported to trigger arrhythmias and alter the clinical course in cardiac contusions by causing molecular and biochemical changes (22). Therefore, to identify pathological changes at the cellular level is very important for the development of treatment protocols.

Oxidative stress plays a critical role in hypoxic-ischemic injury and oxidant-mediated damage in tissue can be detected by the plasma levels of AOPP (25). Several studies have reported that plasma levels of AOPP, an oxidative stress marker, increased in patients with acute coronary syndromes. Moreover, long-term follow-up of plasma AOPP levels in these patients is an effective marker in the estimation of the prognosis (25-27). In our study, there was a significant increase in serum levels of AOPP in the CONT group relative to the control group. This shows that oxidative stress plays a role in cardiac injury occurring after a contusion. Serum levels of AOPP significantly decreased in all treatment groups. However, statistically significant differences were not found between treatment groups.

An excessive release of cardioprotective NO has a negative effect on the circulatory system and myocardial damage is markedly diminished by the use of selective and non-selective NOS inhibitors
(9). Particularly, it was shown that selectively effective aminoguanidine increased myocardial congestion by significantly reducing the increase of $\mathrm{NO}$ and preventing the heart's contractile dysfunction $(9,28)$. In an experimental study, the authors reported that cardiac dysfunction development was accompanied by an increased myocardial iNOS activity. These authors suggested that aminoguanidine significantly decreased iNOS activity and improved left ventricular performance in myocardial stunning (29). In our study, it was determined that AG and MP treatment significantly decreased iNOS expression relative to CONT group. However, it appeared that combined therapy of AG and MP reduced iNOS expression more noticeably as statistically relative to all other treatment groups (CONT and CONT $+\mathrm{AG}+\mathrm{MP})$. This showed that combined treatment was significantly effective against the excessive release of NO.

Myocardial ischemia-reperfusion injury can lead to cell death with apoptosis $(30,31)$. The Bcl-2 family is a group of important apoptosis-regulating proteins and an over expression of Bcl-2 proteins plays a vital role in stopping the pro-apoptosis signal production (31). Steroids are known to prevent apoptosis subsequent to myocardial ischemia by increasing the expression of $\mathrm{Bcl}$ (6). Steroids act as anti-inflammatory agents through the reduction of early inflammatory processes and have also been shown to be cardioprotective in myocardial injury associated with ischemia and cardiac surgery $(32,33)$. One study has suggested that giving a single dose of MP $(15 \mathrm{mg} / \mathrm{kg})$ before a cardiopulmonary bypass surgery resulted in an improved myocardial function (32). In the neonatal period, a $30 \mathrm{mg} / \mathrm{kg}$ single dose of MP prior to open heart surgery reduced systemic inflammatory responses and was shown to be cardioprotective (33). In our study, after an application with a high-dose of MP in the early period after BCT it was continued with low-dose steroid therapy. We determined that the use of AG and MP decreased Bcl-2 expression, but this situation was not statistically significant compared to the CONT group. Given that the combined treatment significantly increased the expression of 
Bcl-2 relative to the other treatment groups, it suggested that a combination of therapy might further prevent apoptosis that might play an active role in myocardial damage.

In conclusion, an excessive NO release, reactive oxidation, and apoptosis are important elements in myocardial damage occurring after BCT. Combined usage of AG, a selective iNOS inhibitor, with MP prevented apoptosis by specifically increasing the Bcl-2 expression in cardiac contusions; it also significantly inhibited the release of NO that was significantly increased after a contusion. Therefore, the combined usage of high-dose steroid therapy with selective iNOS inhibitors in patients with cardiac contusions in the early period seems to be a more effective cardioprotective therapy.

\section{References}

1. Battle CE, Hutchings H, Evans PA. Risk factors that predict mortality in patients with blunt chest wall trauma: a systematic review and meta-analysis. Injury 2012; 43 (1): 8-17.

2. Wang ND, Stevens MH, Doty DB, Hammond EH. Blunt chest trauma: an experimental model for heart and lung contusion. J Trauma 2003; 54 (4): 744-748.

3. Bertinchant JP, Combes N, Polge A et al. Prognostic value of cardiac troponin $\mathrm{T}$ in patients with both acute and chronic stable congestive heart failure: comparison with atrial natriuretic peptide, brain natriuretic peptide and plasma norepinephrine. Clin Chim Acta 2005; 352 (1-2): 143-153.

4. Mueller M, Vafaie M, Biener M, Giannitsis E, Katus HA. Cardiactroponin T. Circ J 2013; 77 (7): 1653-1661.

5. Huang WC, Yang CC, Chen IH, Liu YM, Chang SJ, Chuang YJ. Treatment of Glucocorticoids Inhibited Early Immune Responses and Impaired Cardiac Repair in Adult Zebra fish. PLoS One 2013; 8 (6): e66613.

6. Xu B, Strom J, Chen QM. Dexamethasone induces transcriptional activation of Bcl-xL gene and inhibits cardiac injury by myocardial ischemia. Eur J Pharmacol 2011; 668 (1-2): 194-200.

7. Sun J, Li SH, Liu SM et al. Improvement in cardiac function after bone marrow cell thearpy is associated with an increase in myocardial inflammation. Am J Physiol Heart Circ Physiol 2009; 296 (1): H43-50.

8. Zhang Y, Bissing JW, Xu L et al. Nitric oxide synthase inhibitors decrease coronary sinus-free radical concentration and ameliorate myocardial stunning in an ischemia-reperfusion model. J Am Coll Cardiol 2001; 38 (2): 546-554.

9. Luo Y, Cha DG, Liu YL, Zhou SF. Differential effects of selective and nonselective nitricoxide synthase inhibitors on the blood perfusion of ischemiareperfused myocardium in dogs. Med Sci Monit Basic Res 2013; 19: 181-186.

10. Mihailidou AS, Loan Le TY, Mardini M, Funder JW. Glucocorticoids activate cardiac mineralocorticoid receptors during experimental myocardial infarction. Hypertension 2009; 54 (6): 1306-1312.

11. Parlakpinar H, Ozer MK, Acet A. Effect of aminoguanidine on ischemia-reperfusion induced myocardial injury in rats. Mol Cell Biochem 2005; 277 (1-2): 137-142.

12. Guzel A, Basaran UN, Aksu B et al. Protective effects of S-methylisothiourea sulfate on different aspiration materials-induced lung injury in rats. Int J Pediatr Otorhinolaryngol 2008; 72 (8): 1241-1250.

13. Teng D, Pang QF, Yan WJ, Zhao Xin W, Xu CY. The harmful effect of prolonged high-dose methylprednisolone in acute lung injury. Int Immunopharmacol 2013; 15 (2): 223-226.

14. Eroglu C, Yildiz OG, Saraymen R, Soyuer S, Kilic E, Ozcan S. Aminoguanidine ameliorates radiation-induced oxidative lung damage in rats. Clin Invest Med 2008; 31 (4): E182-188.
15. Raghavendran K, Davidson BA, Helinski JD et al. A rat model for isolated bilateral lung contusion from blunt chest trauma. Anesth Analg 2005; 101 (5): 1482-1489.

16. Miller PR, Croce MA, Bee TK et al. ARDS after pulmonary contusion: accurate measurement of contusion volume identifies high-risk patients. J Trauma 2001; 51: 223-228.

17. Battistella FD, Benfield JR. Blunt and penetrating injüries of the chest wall, pleura and lungs. In. Shield Tw. General thoracic surgery. 5nd Ed. Philadelphia: Williams and wilkins, 2000: 815-863.

18. Locicero I, Mattox KL. Epidemiology of chest trauma. Surg Clin North Am 1989; 69: 15-19.

19. Bansal MK, Maraj S, Chewaproug D, Amanullah A. Myocardial contusion injury: redefining the diagnostic algorithm. Emerg Med J 2005; 22 : 465-469.

20. Mascaro M, Trojian TH. Blunt cardiac contusions. Clin Sports Med 2013; 32 (2): 267-271.

21. Vougiouklakis T, Peschos D, Doulis A, Batistatou A, Mitselou A, Agnantis NJ. Sudden death from contusion of the right atrium after blunt chest trauma: case report and review of the literature. Injury 2005; 36 (1): 213-217.

22. Kaye P, O'Sullivan I. Myocardial contusion: emergency investigation and diagnosis. Emerg Med J 2002; 19 (1): 8-10.

23. Elie MC. Blunt cardiac injury. Mt Sinai J Med 2006; 73 (2): 542-552.

24. Malangoni MA, McHenry CR, Jacobs DG. Outcome of serious blunt cardiac injury. Surgery 1994; 116: 628-632.

25. Danzig V, Míková B, Kuchynka $P$ et al. Levels of circulating biomarkers at rest and after exercise in coronary artery disease patients. Physiol Res 2010; 59 (3): 385-392.

26. Skvarilova M, Bulava A, Stejskal D, Adamovska S, Bartek J. Increased level of advanced oxidation products (AOPP) as a marker of oxidative stress in patients with acute coronary syndrome. Biomed Pap Med Fac Univ Palacky Olomouc Czech Repub 2005; 149: 83-87.

27. Feng Y, Shen C, Ma G et al. Prolonged pain to hospital time is associated with increased plasma advanced oxidation protein products and poor prognosis in patients with percutaneous coronary intervention for ST-elevation myocardial infarction. Heart Vessels 2010; 25 (5): 374-378.

28. Wu MS, Liang JT, Lin YD, Wu ET, Tseng YZ, Chang KC. Aminoguanidine prevents the impairment of cardiac pumping mechanics in rats with streptozotocin and nicotinamide-induced type 2 diabetes. $\mathrm{Br} \mathrm{J}$ Pharmacol 2008; 154 (4): 758-764.

29. Wildhirt SM, Schulze C, Conrad N, Kornberg A, Horstman D, Reichart B. Aminoguanidine inhibits inducible NOS and reverses cardiac dysfunction late after ischemia and reperfusion-implications for iNOS-mediated myocardial stunning. Thorac Cardiovasc Surg 1999; 47 (3): 137-143.

30. Jin HB, Yang YB, Song YL, Zhang YC, Li YR. Protective roles of quercetin in acute myocardial ischemia and reperfusion injury in rats. Mol Biol Rep 2012; 39 (12): 11005-11009.

31. Gao J, Zhao L, Wang Y, Teng Q, Liang L, Zhang J. Effect of limb ischemic preconditioning on myocardial apoptosis-related proteins in ischemia-reperfusion injury. Exp Ther Med 2013; 5 (5): 1305-1309.

32. Liakopoulos OJ, Schmitto JD, Kazmaier S et al. Cardiopulmonary and systemic effects of methylprednisolone in patients undergoing cardiac surgery. Ann Thorac Surg 2007; 84: 110-118.

33. Keski-Nisula J, Pesonen E, Olkkola KT et al. Methylprednisolone in neonatal cardiac surgery: reduced inflammation without improved clinical outcome. Ann Thorac Surg 2013; 95 (6): 2126-2132.

Received August 18, 2013. Accepted September 5, 2013. 